\title{
PSYCHOLOGICAL ASPECTS OF TRAINING FOR LEISURE
}

\author{
W. RAMSAY, B.Sc., M.Ed. \\ Lecturer in Psychology, Jordanhill College, Glasgow
}

In the course of this paper $I$ intend to examine the psychological aspects of training for leisure under two main headings, Learning and Motivation. These two are not, of course, mutually independent. Complex learning, at least, is heavily dependent on the motivation of the student; and conversely, some psychologists would maintain that without learning, the variety of human motives would not be nearly so great as it is.

Firstly, consider the reinforcement face of learning (as opposed to the identification, or modelling face). The reinforcement model of learning is, of course, the conditioning model; specifically an operant conditioning model in which any desired piece of behaviour is "reinforced" by the presentation of a pleasurable stimulus.

Complex behaviours may be trained by the techniques of chaining (either forward or backward) or shaping (in which reinforcement is regularly withheld until some further incremental improvement in the behaviour occurs) as appropriate. These techniques are well described in the works of B. F. Skinner and others. Such an approach need not be restricted to physical skills. The establishment of concepts and the training of judgment may also be shaped by requiring finer and finer discriminations to be made before reinforcement is presented. Immediacy of reinforcement is essential to the success of these approaches; differences in coaching quality may be, in this model, simply differences in the skills of analysing behaviour into simple components and skill in timing and devising appropriate reinforcements. Since success is vital to maintaining or increasing the level of motivation such coaching skills are obviously important. "Individual differences" will imply, among other things, that different analyses and different types of reinforcement will apply to different pupils, consequently intensive training in terms of pre-conceived targets is unlikely to achieve substantial success in terms of achievement and motivation.

To some extent skills may be acquired by the second process, modelling, at least in basic forms. How far this succeeds without the intervention of a coach will depend on the capacity of the child to put himself in another's place (and the younger the child the harder this is) and the degree to which the skill is amenable to intellectualisation. Acquisition of concepts and judgmental skill will generally be slower in such cases because the Model's performance cannot be guaranteed to be free of irrelevant and perhaps hampering idiosyncracies, and in any case his behaviour and decisions will be hedged round with associated but irrelevant behaviours whose irrelevance will be required to be established painfully as part of the pupil's concept, so to speak.

It is in the realm of attitudes, values and ethics that identification learning has its major role to play. While to some extent concepts of correct behaviour and acceptable value statements may be inculcated by suitable reinforcement-type discrimination training there is a powerful body of opinion among psychologists that the values and attitudes of society, as mirrored by the parents, are adopted and internalised by the child via a process, sometimes called introjection, which cannot be equated with specific training or even imitation. The extent to which such a process is possible in coaching or training is debatable - it is probably highly unlikely given the period of contact and emphasis on "training". However, some process of identification, of adopting the person of the coach, so to speak, is probably possible and even likely for some individuals. The extent to which identification takes place will depend on the character of the coach, the extent to which his values in other areas are recognised by the child, the consistency of his behaviour and so on. Howard Kelman uses the term in a special sense, not of identity but of reciprocity in which a role relationship is involved.

Internalization of values, i.e. their incorporation into the individual's own value system and their maintenance without social support, is dependent on the degree of congruence between the new values and the existing value system, or the ease with which they may be modified to fit. Adding to, or adapting an existing value system at this level is, of course, the most difficult of tasks.

In summary, whether an individual becomes a devotee of any particular activity will be a function of his success in acquiring its skills, the attractiveness of the coach as an identificand and/or member of an appropriate role relationship, or both; and the extent which the values of the coach, and indeed of typical devotees, are consistent with his own value system.

There are numerous cases where reinforcement may act more against the interests of safe and fruitful pursuit of an activity than in its favour. For example:-

giving up the search for map and whistle not going back to the car for your lifejacket 
(reinforced by immediate departure in each case). taking your gloves off

unroping (reinforced by increased freedom of movement).

bringing down an opponent illegally

(reinforced by conversion of a creative and threatening breakaway into a set-piece).

The converse behaviour in such cases is seldom reinforced in concrete terms, or with any immediacy. Knowing what the rules are is not the same as being ethical; having a concept of safe behaviour and knowing how to cope with crises is not the same as being safety-conscious. Ethics and safety-consciousness are matters of attitudes and values, and are more likely, in view of the limitations of reinforcement training, to be "caught" from someone else. Apart from that, the control of the presentation of, for instance, weather conditions, is beyond us in training and the margin of "playing safe" narrows constantly with increase of skill and perfection of judgment. In consequence, anything less than an internalization of values is potentially dangerous, and the promotion of internalization is, as we have seen, a very difficult task. Role relationships may remain unactivated, external pressures may force compliance with unethical behaviour and dangerous decisions.

In practical terms of attitude change here I am not sure that safety-consciousness is always approached in the right way. The more fear inspiring the propaganda the less effective it is in general. Great emphasis is laid on the hostility of special environments, e.g. the Cairngorms in winter, and the possible consequences if ... or unless ... Such an approach does, I believe, two disservices to the cause of safety. Firstly, it detracts from the realisation that any environment is dangerous at any time.

Secondly, the emphasis is laid on fear-inspiration. Such an approach can lose effectiveness by frightening people away from anything to do with safety and safety precautions. The flight may not be total or complete, indeed it rarely will be, but the avoidance tendency will be there; "safety precaution" becomes equated with the admissions of the possible imminence of one's own death, for instance. If we require people to act safely and adopt safety-conscious attitudes then the place to begin is in the everyday "safe" environments and the presentation should make use, as far as possible, of positive messages and minimise the fear aspect. For example:-

\footnotetext{
"You can freeze to death in no time on the mountains unless you wear..." might be replaced by

"It gets colder as you go higher, so you should carry an extra sweater to keep you warm. Nothing ruins an outing like getting cold."
}

Even the colours of some outdoor wear suggest the possibility of getting lost. Perhaps an emphasis on "fashion colours" rather than safety would appeal to a more useful set of motives. As a general rule people should be motivated into careful behaviour, not frightened away from it.

\section{Motivation}

At this point a closer look at motivation is perhaps in order. At the outset I should make it clear that "motivation" is being used in a particular sense, which is not the popular one. People speak of being "motivated to do" something, or of "unconscious motives", or of "good and bad motives" as if a motive were a kind of human spring mechanism which impelled people to perform certain specific kinds of acts. My own point of view is that motives operate in the sense of a payoff in terms of tension reduction and the nature of the motive is related to the cause of the tension rather than the type of action. Reinforcing events are events which serve to reduce tension, speaking in these terms, hence the relationship between motivation and learning. This is not to deny totally that spontaneously generated activity is possible.

In terms of motivation, leisure activities may be adopted because their performance satisfies some need or reduces some tension in the individual. The nature and origins of these needs and tensions has been the subject of attention from philosophers and psychologists for many years. Most systems that deal with motivations recognise two principal subdivisions, into biological-survival and acquired; although where any given motive belongs in any one classification is not always clear. Numerous hierarchies of motives have been proposed, but perhaps the only agreement is on the primacy of biological needs. Attempts to teach, train, instruct or carry out any activity by exploiting acquired or social drives will be blocked if the trainee is in a state of acute biological tension. Undoubtedly the latter is the case in poor conditions outdoors so that performance of survival skills may suffer. An additional complication is that such skills are necessarily gained in much less severe conditions than those in which success in their exercise becomes critical. In a crisis, not only does the individual have to perform under different external conditions, he is at the mercy of a changed internal environment as well. Safety demands that he remains in an environment whose hostility may have been impressed on him in the most frightening terms! Survival motives may then prejudice his safety because they are satisfied by maladaptive behaviour, e.g. keeping on the move, getting "closer to home", thrashing about to keep warm and so on.

Leisure activites are generally indulged in for other reasons than biological ones, however. Needs for 
affiliation will be satisfied by behaviour which promotes affiliation to a desired group, for instance; needs for self esteem by achievement or superiority in some particular activity. Many models for the functioning of motives in such situations have been proposed.

An activity may become valued for its own sake because of the operation of the "concept of competence".

In Adlerian psychology the idea of striving for superiority is paramount. In the quest for self-perfection individuals may compensate for weakness in one area by excelling, and striving to increase their excellence in others. In a limited situation all the motivational eggs may end up in one basket, so to speak, and people in such a case may direct themselves towards being the world's best mountaineer, pilot, skin-diver etc., rather than the world's oldest. The same is true, of course, where any motive is operating, if arousal of the need is regular, frequent and intense. Such an individual in a group, especially if he or she is a valued member of the group (more than likely, on the grounds of skill), represents a potential hazard to all the members. Further, narrowness of specialization coupled with the onset of age or injury may have catastrophic consequences for such an individual. To that extent intensive training, if devoted to a single activity, may render some people a disservice by routing them into a narrow path of interests, motivated by the success that may attend the training session.

The implications for the presentation to children, at as early an age as possible, of as wide a variety of potential activities as possible is, I hope, fairly obvious. Intensive training ought to be delayed at least until a range of activities is established strongly enough that threads can be readily picked up again in the future. 